$\Rightarrow$ SUPERATOMS

\title{
Open shells open doors
}

\section{4 \\ fascinating discoveries and surprises are out there in the 'darkness' of our reaction cocktails}

The electronic structure of a single atom can often be mimicked by atom-precise metal clusters of an entirely different element. Akin to having a noble gas electronic configuration, these clusters referred to as superatoms - usually have $2,8,18,20,34,40,58$ or 68 (and so on) valence electrons that correspond to completely filled 1S, 1P, 1D, 2S, 1F, 2P, $1 \mathrm{G}$ and 2D 'jellium' shells. Preparing large superatoms with partially filled jellium orbitals has proven difficult but not too difficult for Roland A. Fischer and colleagues, who describe, in Angewante Chemie International Edition, the characterization of $\left[\mathrm{Cu}_{43} \mathrm{Al}_{12}\right]\left(\mathrm{C}_{5} \mathrm{Me}_{5}\right)_{12}$, a 67 valenceelectron superatom complex.

It has long been known that bulk intermetallics can mimic the behaviour of another metal element. In much the same way that $\mathrm{Al}_{13} \mathrm{Fe}_{4}$

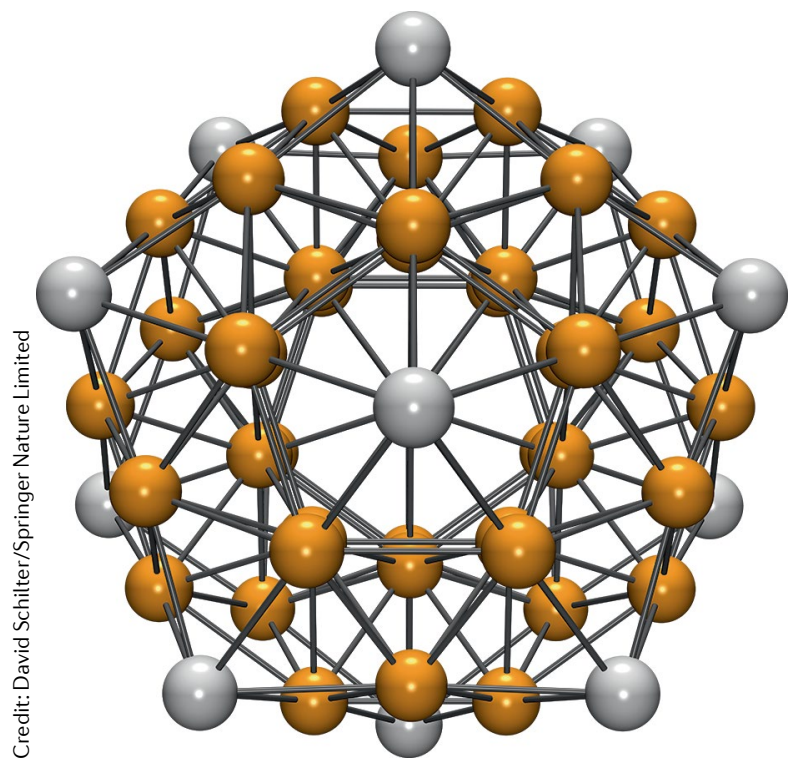

can mimic the precious metal catalyst $\mathrm{Pd}$, we can think of the superatom $\mathrm{Al}_{13}$ (just $1 \mathrm{e}^{-}$shy of 40 jellium electrons) as an analogue of a $\mathrm{Cl}$ atom $\left(1 \mathrm{e}^{-}\right.$shy of an $18 \mathrm{e}^{-}$[Ar] configuration). Superatoms can also bear organic ligands, and prominent among such superatom complexes is $\left[\mathrm{Al}_{50}\right]\left(\mathrm{C}_{5} \mathrm{Me}_{5}\right)_{12}-\mathrm{a}$ 138 electron complex with an $\left[\mathrm{Al}_{38}^{0}\right]$ core stabilized by a dozen $\mathrm{Al}^{\mathrm{I}} \mathrm{C}_{5} \mathrm{Me}_{5}$ carbene-like $2 \mathrm{e}^{-}$donors. The team guessed that these metalloligands might also be able to stabilize cores composed of different metals as part of heterometallic superatom complexes. Of their efforts to make these, Fischer recalls "one motivation was to better understand structurebonding-property relationships in the regime between metal-rich complexes and ligated mixed-metal nanoparticles."

Fischer's team combined $\left[\mathrm{Cu}^{\mathrm{I}}(\text { mesityl })\right]_{5}$ and $\left[\mathrm{Al}^{\mathrm{l}} \mathrm{C}_{5} \mathrm{Me}_{5}\right]_{4}$ to give $\left[\mathrm{Cu}_{43}^{0} \mathrm{Al}_{12}^{\mathrm{I}}\right]\left(\mathrm{C}_{5} \mathrm{Me}_{5}\right)_{12}$ as highly air-sensitive crystals. The X-ray structure features metal atoms in a two-shell icosahedral structure with a central $\mathrm{Cu}$ residing inside a $\left\{\mathrm{Cu}_{12}\right\}$ cage, which itself is in the middle of a $\left\{\mathrm{Cu}_{40} \mathrm{Al}_{12}\right\}$ cage. In terms of metal atoms, it turns out that 55 is an auspicious 'magic' number, shared also by the almost isostructural complex $\left[\mathrm{Pd}_{55}^{0}\left(\mathrm{P}^{i} \mathrm{Pr}_{3}\right)_{12}(\mathrm{CO})_{20}\right]$. However, in terms of electrons, it is at first unclear how we should look at $\left[\mathrm{Cu}_{43}^{0} \mathrm{Al}_{12}{ }_{12}\right]\left(\mathrm{C}_{5} \mathrm{Me}_{5}\right)_{12}$. If we formulate it as a $\left[\mathrm{Cu}_{43}^{0}\right]$ core with $12 \mathrm{Al}^{\mathrm{l}} \mathrm{C}_{5} \mathrm{Me}_{5}$ ligands, each $\mathrm{Cu}^{0}$ would contribute $1 \mathrm{e}^{-}$ to a jellium electron count of $43-$ quite removed from a 'stable' count of 40. Accordingly, Fischer teamed up with the group of Jean-Yves Saillard, whose spin-polarized density functional theory calculations revealed that all 55 metals in the simplified model $\left[\mathrm{Cu}_{43}^{0} \mathrm{Al}^{1}{ }_{12}\right]$ $\left(\mathrm{C}_{5} \mathrm{H}_{5}\right)_{12}$ are best considered as a superatom with 67 jellium electrons. We can presume that $\left[\mathrm{Cu}^{0}{ }_{43} \mathrm{Al}^{1}{ }_{12}\right]$ $\left(\mathrm{C}_{5} \mathrm{Me}_{5}\right)_{12}$ has the same count, and its 3 unpaired electrons $(S=3 / 2)$ cause it to exhibit temperature-independent paramagnetism. Such open-shell organometallics are often kinetically unstable, but in the present case the metal core benefits from the steric protection afforded by its organic exterior. Indeed, this work teaches us that stable superatoms can assume a variety of electronic structures, including those with partially filled jellium orbitals - the beginnings of a conduction band.

Fischer and colleagues are now targeting other 55 atom clusters like $\left[\mathrm{Cu}_{43-x} \mathrm{Al}_{12+x}\right]\left(\mathrm{C}_{5} \mathrm{Me}_{5}\right)_{12}$, which should be feasible given that elemental $\mathrm{Cu}$ and $\mathrm{Al}$ have similar (fcc) structures. We could then access complexes with a wide variety of jellium electron counts. Applications in catalysis, however, would likely require larger and less-passivated clusters with surface hydrido ligands and sites for substrate binding. Towards these goals, Fischer notes "the unique open-shell superatom properties of $\left[\mathrm{Cu}_{43}^{0} \mathrm{Al}_{12}^{\mathrm{r}}\right]\left(\mathrm{C}_{5} \mathrm{Me}_{5}\right)_{12}$ suggest that fascinating discoveries and surprises are out there in the 'darkness' of our reaction cocktails."

David Schilter

ORIGINAL ARTICLE Weßing, J. et al. The Mackaytype cluster $\left[\mathrm{Cu}_{43} \mathrm{Al}_{12}\right]\left(\mathrm{Cp}^{*}\right)_{12}$ : open-shell 67 electron superatom with emerging metal-like electronic structure. Angew. Chem. Int. Ed. https:// doi.org/10.1002/anie.201806039 (2018) 